\title{
On Close Reading from the Perspective of Rhetoric
}

\author{
Tiping Su \\ Department of College English, Huaiyin Teachers College \\ Huai'an 223001, Jiangsu, China \\ E-mail: sue6415@126.com
}

\begin{abstract}
Close reading places great emphasis on the particular over the general, paying close attention to individual words, syntax, and the order in which sentences and ideas unfold as they are read. And rhetoric is the art of using language as a means to persuade. Along with grammar and logic or dialectic, rhetoric is one of the three ancient arts of discourse. Rhetoric inputs meanings into the discourse or text while close reading outputs the meanings from the discourse or text, which are the opposite processes of constructing meanings. Close reading was pioneered by the New Critics but commonly employed by late scholars and rhetoric was and is paid attention to by the scholars, too, which are closely related to each other. Rhetoric is categorized into textual, contextual and intertextual rhetoric, this paper tries to explore the hidden essence of the text, reveal the real motivation of the author and expose the artistic connotation of the works through close reading.
\end{abstract}

Keywords: Close reading, Textual rhetoric, Contextual rhetoric, Intertextual rhetoric

Close reading was pioneered by I.A. Richards and his student William Empson, later developed further by the New Critics. It "describes the careful, sustained interpretation of a brief passage of text" and "places great emphasis on the particular over the general, paying close attention to individual words, syntax, and the order in which sentences and ideas unfold as they are read" and "A truly attentive close reading of a two-hundred-word poem might be thousands of words long without exhausting the possibilities for observation and insight. To take an even more extreme example, Jacques Derrida's essay Ulysses Gramophone, which J. Hillis Miller describes as a "hyperbolic, extravagant... explosion" of the technique of close reading, devotes more than eighty pages to an interpretation of the word "yes" in James Joyce's great modernist novel Ulysses". (Wikipedia) Rhetoric, according to The American Heritage Dictionary, means "skill in using language effectively and persuasively". In fact, it has a long history and in the western tradition "rhetoric is the art of using language as a means to persuade. Along with grammar and logic or dialectic, rhetoric is one of the three ancient arts of discourse. From ancient Greece to the late 19th Century, it was a central part of Western education, filling the need to train public speakers and writers to move audiences to action with arguments. The very act of defining has itself been a central part of rhetoric, appearing among Aristotle's Topics. The word is derived from the

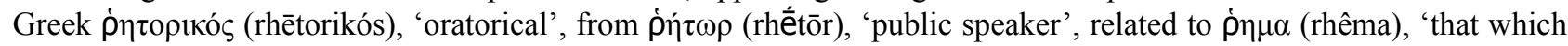
is said or spoken, word, saying', and ultimately derived from the verb غ $\rho \tilde{\omega}$ (erô), 'to speak, say'.” (Wikipedia) In its broadest sense, rhetoric concerns human discourse. Luo Xiao-suo (2004), a modern Chinese linguist, also wrote in his Modern Rhetoric "rhetoric is the methods, skills or rules of using language and linguistic styles in order to better express one's thoughts or feelings in some special occasion." The definitions of rhetoric show that rhetoric is really the skills of using language, especially words to express one's opinions and try to persuade others. These definitions of "close reading" and "rhetoric" actually reveal the connection between them, that is, rhetoric inputs meanings into the discourse or text while close reading outputs the meanings from the discourse or text, which are the opposite processes of constructing meanings. Paul de Man, as a master of deconstruction, even paid much attention to rhetoric of text, too. And today some American universities, Berkeley for example, set up department of rhetoric and can grant the doctoral degree. These phenomena can prove the importance of rhetoric in the western world. Therefore, this paper will analyze the functions of rhetoric from three levels through close reading.

\section{Textual Rhetoric}

Textual rhetoric is not only a term of rhetoric but also a term of literary criticism, mass communication and pragmatics, etc. In the eyes of literary critics, rhetorical texts include fictions, poems, prose and dramas and so on while they cover texts of speech and debate in the scholars' eyes of communication. But compared with that of literary criticism and mass 
communication, the domain of textual rhetoric in rhetoric is much broader, which can refer to any complete and independent rhetorical text created for communication. The textual rhetoric can be as short as a word, for instance, an editorial on the unsuccessful run of Lyndon Johnson for the presidency from Evening Star in 1968 saying: "Wonderful!", and at the same time, it may be as long as a speech or a novel, such as Lincoln's Address at Gettysburg on November 19, 1863 or James Joyce's novel Ulysses.

Textual rhetoric is the most common and essential techniques of rhetoric as well as a kind of rhetorical techniques easy to be appreciated by readers. Generally speaking, readers can understand this kind of rhetoric directly and needn't connect other texts. Simile, metaphor and hyperbole, etc. are of these rhetorical techniques. E.g.

1). Earth looks like a big blue marble...

Readers can get this image easily because they know that three quarters of the earth is covered with water and looks blue in the sky, so the author pictures the earth with such a simile.

2) ....it seems to me that the ceaseless rhythm of the wheels is like scissors cutting a three-thousand-mile rip through my life.

In this sentence "the ceaseless rhythm of wheels" is compared with "scissors" and the sound is just like that from "scissors" cutting something which penetrates into my heart and divides my life into two half. It reflects the writer is reluctant to depart from his first half life and afraid of the coming half life.

3). For what, I sometimes wonder; so that she can struggle to breathe through most of her life feeling half her strength, and then die of self-poisoning, as her grandfather did?

Breathing is so natural for every normal person, but here the author wrote "struggle to breathe", which confused and surprised readers. Why to struggle to breathe? From the latter part, readers can read the worry and pain of the author because her father had died from smoking while her daughter was smoking then.

4) ....he continued to look like a poor, overweight, hardworking colored man with too large a family, black, with a very white cigarette stuck in his mouth.

"Overweight" is the euphemism of "fat". Most persons dislike to be described as "fat", and here the author didn't also like to describe her father as "fat". Euphemism is closely related to the social progress and the boost of people's living standards. As a phenomenon of sociolinguistics, it has some important social functions, such as naming taboo, politeness or disguise, which is the product of psychology of social culture and that of communication, and the author tried to disguise her father's fault in this example.

The above examples show that textual rhetoric can make the text vivacious, lively and visual, and stimulate readers' imagination, but can't be understood literally. Textual rhetoric is a commonly used technique, which exists in every text. If readers can read between the lines and try to dig out the implications of the text, they can find the beauty of the text. Compared with contextual rhetoric, however, it is a comparatively easier technique to understand.

\section{Contextual rhetoric}

Context covers two respects: macro-context and micro-context, the former refers to social and cultural context, which involves in every domains of human life, such as basic necessities of life, folkways and values, etc. that is, non-linguistic context. Micro-context is linguistic context, which refers to the text where the language is used in the language learning. (FENG Shi-mei, 2007: 102) In other words, context refers to the relevant constraints of the communicative situation that influence language use, language variation and discourse. But rhetorical techniques are analyzed only within the linguistic context in this paper. Some rhetorical techniques are difficult to understand and appreciate without context, such as irony, pun and empathy, etc. E.g.

1). I realize now that as a child I sat by, through the years, and literally watched my father kill himself surely one such victory in my family, for the prosperous leaders who own the tobacco companies, is enough.

From this sentence itself, readers can't find the connection between the death of "my father" and "one such victory". They may ask what the victory is and who "the prosperous leaders" are. Connected with the context, readers find "the prosperous leaders" are the boss of tobacco companies, and "my father" was killed by the products — cigarettes —of "the leaders". In this sense, it is really the victory of "the leaders" over "my father", while which is a so cruel victory with cost of a life. What's more, the author's daughter was dogging her grandfather's footsteps. Therefore, readers can easily read the rage and irony from this sentence.

2). And, speaking of the science of Life, have you got the cucumber sandwiches cut for Lady Bracknell? (Wilde, 1940: 415)

When some readers read this sentence, they may wonder what "the science of Life" means. Based on the latter part of this sentence, they may guess it means "techniques of life", which, however, is different from "science of Life" and does not agree with the context on reflection. Date back to a sentence before this one, we can find "I don't play 
accurately any one can play accurately but I play with wonderful expression. As far as the piano is concerned, sentiment is my forte. I keep science for life. (Wilde, 1940: 415)" Here science in fact means "accurate", and which is really the characteristic of "science", so "the science of Life" is "the scientific style of life" but not "techniques of life". Typical of contextual rhetoric are these two examples, whose implications can only be found based on the context.

3). They were all young men and they were saving their country. The second army was being reformed beyond the Tagliamento. They were executing officers of the rank of major and above who were separated from their troops. They were also dealing summarily with German agitators in Italian uniform. They wore steel helmets. Only two of us had steel helmets. Some of the carabinieri had them. The other carabinieri wore the wide hat. Airplanes we called them. We stood in the rain and were taken out one at a time to be questioned and shot. So far they had shot everyone they had questioned. The questions had that beautiful detachment and devotion to stern justice of men dealing in death without being in any danger of it.

This paragraph narrated the fact that the Italian military officers and soldiers acted with utter disregard for human life in the First World War, because they may shoot any soldiers and officers retreating from the battlefield and anyone that they suspected to be German spies, without asking about the causes. The author said "they were saving their country", but "they" never went to the battlefront and stayed at the safe rear area and "they" were really committing many acts harmful to their country. The author also said "beautiful detachment and devotion to stern justice of men dealing in death without being in any danger of it", but in fact what "they" did is indeed evil, subjective and unfair. In this text, although the author didn't reveal his feelings with some special words, but readers can read the irony and satire in the context, which is the characteristic of situation irony. The context plays a very important role in understanding and appreciating the implications of this kind of texts.

\section{Intertextual Rhetoric}

"Intertext" (hu wen in Chinese) has been existing in the traditional Chinese rhetoric for thousands of years. It is a special rhetorical technique in Ancient Chinese Language that refers to the words in the adjacent two sentences combined to express the complete meaning, such as "qin shi ming yue han shi guan", a poem meaning "the moon of Qin and Han Dynasty shines on the Pass of Qin and Han Dynasty" but not "the moon of the Qin Dynasty shines on the Pass of Han Dynasty" as some westerns translated, and "gan shi hua jian lei, hen bie niao jing xin", translated as "Even flowers seem to shed tears/For the sadness of our time./The very birds/Grieve at the sight of people/Parting from their beloved" by Yang Hsien-yi and Gladys Yang from a poem "A Spring View" of Du Fu, the famous poet of Tang Dynasty. But "intertextual rhetoric" in this paper comes from the term created by Julia Kristeva, "intertextuality (intertextualité)", which "is the shaping of texts' meanings by other texts. It can refer to an author's borrowing and transformation of a prior text or to a reader's referencing of one text in reading another." "The term 'intertextuality' has, itself, been borrowed and transformed many times since it was coined by poststructuralist Julia Kristeva in 1966. As critic William Irwin says, the term 'has come to have almost as many meanings as users, from those faithful to Kristeva's original vision to those who simply use it as a stylish way of talking about allusion and influence'. (Wikipedia) From the perspective of rhetoric, it refers to the relationship that texts depend on and interact with each other or the relationship between "a text" and "other text". (TANG\&XU, 2006: 108) Intertextual rhetoric is different the textual and contextual rhetoric, and which is hard or even impossible to be understand without other texts. However, there are various ways to represent intertextuality, such as quotation, allusion, reference, pastiche, parody, pirate and all kinds of copies. That is to say, if readers want to catch this kind of texts, they have to draw into other texts. Readers have to read not only between the lines but more important between the texts and trace the interactional texts. E.g.

1). To lie or not to lie - the doctor's dilemma

At a glance of the sentence, into readers' mind springs another sentence that "to be or not to be, that's the question", which comes from HAMLET, the most famous drama of Shakespeare. Any knows the drama knows "to be or not to be" is an eternal dilemma for Hamlet. This sentence is typical of pastiche of that of Shakespeare, which evidently points out the doctor's problem without too many words.

2). I don't play accurately any one can play accurately but I play with wonderful expression. As far as the piano is concerned, sentiment is my forte. I keep science for life. (Wilde, 1940: 415)

When readers meet "Science" in this sentence, they may feel quiet abrupt because this word cannot get a long with the context. In fact, Wilde was insinuating the dispute of the position between humanities and science during the middle and end of Victoria era. This dispute originated from that between Thomas Henry Huxley (1825-1895) and Mathew Arnold (1822-1888). Huxley, as an advocator of science, spared no effort to advocate drawing natural science into liberal education and made the famous speech Science and Culture in 1880 to elaborate his idea, while Arnold's Literature and Science made in Cambridge in 1882 was diametrically opposed to Huxley's speech and expressed stingingly to "save mankind from that danger". (Arnold, 1822) Here "danger" actually refers to "science". Oscar Wilde, the famous aesthete, had always been hostile to science. The big word "science" employed in "I keep science for life" is 
to tease the advocate of that time because people will pay no much attention to science in daily life. It is hard to find the satire in this sentence if readers cannot remind of Huxley's and Arnold's texts.

Intertextuality is an important feature of academic papers as well as literary works, which is demanded by rules of scientific propagation and exchanges. Understanding in depth the intertextuality of academic papers is the start point of reading, writing, and evaluating academic papers as well. (Tang \& Xu, 2009: 112) Laurent Jenny (1980) categorized intertextuality of the literary works into omission, hyperbole and inversion and so on. All these methods are employed in academic papers by the authors, too. But intertextuality of academic papers is different from that of literary works because the author of academic paper should tell the source of the sentences or texts cited in his paper.

Intertextuality is "a comprehensive domain which covers various kinds of nameless formula that are hard to trace their origins and the words quoted unconsciously or automatically without quotation marks". The above are some typical examples. In fact, intertextuality exists in every text, in which the sound always interacts with that from other texts and produces more new implications. Readers can trace back to "quoted words" without quotation marks, dig the hidden kernel and construct new meaning for the text.

\section{Conclusion}

Edward Sapir (1921) argued that "language is a cultural, not a biologically inherited, function". This means people will involuntarily accept the other cultural system when they learn another language other than their mother tongue. Rhetoric, as a branch of linguistics, is to study the usage of language and put emphasis on the rules and characteristics of language in communication and is a kind of art of using language. The cultural gap often hinders readers understanding the foreign language and culture, especially the literary language with rhetorical techniques. Readers should spare no pains to appreciate the beautiful words by close reading. Close reading can help readers appreciate literary masterpieces and get access to their souls permeating the words or literary images so the task of close reading is to reveal the true motivation hidden in the texts and show the artistic connotations of the texts.

\section{References}

Arnold, M. (1882). Literature and Science. [Online] Available: http://math.clarku.edu/huxley/comm/19th/Arnold.html.

Feng, Shimei. (2007). Context, Rhetoric and Teaching of Advanced English. Journal of Guangdong Ocean University, 5 .

Jenny, Laurent. (1980). The Strategy of Forms. Cambridge: Cambridge University Press.

Luo, Xiaosuo. (2004). Modern Rhetoric. Kunming: Renmin Press of Yunnan, 17.

Sapir, Edward. (1921). Language-An Introduction to the Study of Speech. [Online] Available: http://www.bartleby.com/186/.

Tang, Jianmin \& Xu Yanzhan. (2006). Intertextuality of Academic Papers and My Reflection. Studies in Dialectics of Nature, 9.

Wikipedia. Close Reading. [Online] Available: http://en.wikipedia.org/wiki/Close_reading.

Wikipedia. Intertextuality. [Online] Available: http://en.wikipedia.org/wiki/Intertextuality.

Wikipedia. Rhetoric. [Online] Available: http://en.wikipedia.org/wiki/Rhetoric.

Wilde, O. (1940). The Best Known Works of Oscar Wilde. New York: Blue Ribbon. 